\title{
Pattern of Molocclusion in Patients Seeking Orthodontic Treatment at Medical Colleges \& Teaching Hospitals of Chitwan, Nepal
}

\author{
Dr Bashu Raj Pandey,' Dr Shailendra Kumar Singh,, Dr Rajan Singh, ${ }^{3}$ Dr Rajeev Mishra, \\ Dr Srijana Mishra, ${ }^{5}$ Dr Bimala Gharti ${ }^{2}$ \\ 'Asst professor/HoD, ${ }^{3}$ Asst professor, Dept of Orthodontics \& Dentofacial Orthopedics \\ 2Professor \& Head, ${ }^{5}$ Asst Professor, Department of Prosthodontics, \\ Chitwan Medical College, Nepal \\ "Head of department, Dept of orthodontics, College of Medical Science, Bharatpur \\ ${ }^{6}$ Dental Surgeon \\ Correspondence: Dr Bashu Raj Pandey; Email: drpandeybr@gmail.com
}

\section{ABSTRACT}

Introduction: Various forms of malocclusion is most common dentofacial abnormality found in human population. People seek tteatment for such abnormalities based on the severity. The objective of this research is to evaluate Pattern of Malocclusion in Patients Seeking Orthodontic Treatment at Medical Colleges and Teaching Hospitals of Chitwan, Nepal.

Materials \& Method: Two hundred thirty nine pre-operative study casts of orthodontic patients aged from 12-50 years selected from 550 patient's records of departments of orthodontics of Chitwan Medical Colleges and Colleges of Medical Sciences, Bharatpur of Chitwan. Standard protocol of Angle's classification of malocclusion was used to classify malocclusion and its attributes were recorded. Pearson's Chi square test was performed to justify the result.

Result: The prevalence of malocclusion were $61.92 \%, 33.47 \%$ and $4.60 \%$ for Angle's class I, Angle's class II and Angle's class III malocclusion respectively. Among various attributes of malocclusion, deep bite had highest frequency with $67.36 \%$ followed by overjet $58.99 \%$, crowding $53.13 \%$ and spacing $35.98 \%$, Anterior cross bite $11.71 \%$ reverse overjet $4.6 \%$, posterior cross bite $1.2 \%$ and scissor bite $0.041 \%$. Pearson Chi square test showed no relation among these attributes and sex and age at $p<.05$.

Conclusion: Angle's class I malocclusion is most prevalent followed by Angle's class II and Angle's class III.

Keywords: Angle's classification, Orthodontic, Pattern of malocclusion, Treatment.

\section{INTRODUCTION}

People strive for healthy and beautiful smile. Unlike old days, situation is changing with much advanced treatment modalities available in the field of dentistry today. The demand for orthodontic treatment is increasing in different regions of different countries. This increase may be due to modernization and economic development. The need of data to understand the prevalence of the condition and people's perception of the malocclusion is imperative and gives us the guidance to allocate the services to the needy. This study will also help in understanding the need of resources.

WHO (1987)defined malocclusion as an handicapping dento-facial anomalies causing disfigurement or impending function and may require treatment when the defect was likely to be a cause of patients' physical and emotional wellbeing.' Angle defines "occlusion as a normal relationship of the occlusal planes of the teeth when the jaws are closed." Malocclusion occurs when the teeth are in incorrect relationship with adjacent teeth and teeth in opposite arch when jaws are closed. The present study used Angles classification for data collection and analysis. Angles classification is considered comparatively easy to use and fairly accurate.

Patients may face several problems when they have malocclusion. Increased risks of caries, periodontal problems, temporomandibular disorder, poor aesthetic appearance, risk of trauma arethe major consequences of malocclusion. ${ }^{8}$ Basha et al. found that malocclusion affected psychological wellbeing of the adolescents leading to avoiding participation in social activities and under performance. ${ }^{2}$ It was documented that Masticatory function is reduced in 
the patients with malocclusion leading to decrease in oral function, disharmony, decreased occlusal force and chewing ability. ${ }^{3}$

The study had been done to examine the prevalence of malocclusion in the patients visiting Orthodontic departments of Chitwan Medical College and Hospital and College of Medical Sciences, Bharatpur. There was no documented study on pattern of malocclusion in this part of geographical area of Nepal thus this study could be significant to understand the pattern and distribution of malocclusion and the need of resources for correcting the condition.

This study provides a good picture of the malocclusion in middle part of Nepal and its need of treatment. The study consists of an analysis of data on over jet, crowding, spacing, and deep bite. It also includesopen bite, bimaxillaryproclination and scissor bite.

\section{MATERIALS AND METHOD}

This is the retrospective study done in study cast of patients who visited departments of Orthodontics and Dentofacial Orthopedics of Chitwan Medical College and College of Medical Sciences in Chitwan, Nepal from 2014 to 2018. Two hundred thirty nine acceptable study casts were selected from 550 case recordsof orthodontic patients. The subjects ranged from 12 to 50 years with the following criteria: (1) permanent dentition with fully erupted intact first molar, (2) patient willing for orthodontic treatment with all pretreatment records, (3) no history of previous orthodontic treatment,(4) absenceof craniofacialanomalies. A standard guidance of Angle's classification was used to classify the cases and casts were measured to record the data. Different Angle's classification of malocclusion with discrepancies in all three planes was studied. Several attributes of malocclusion included for the study of the nature of malocclusion were:over jet, spacing, crowding, deep bite, open bite. In addition other problems like bimax protrusion, retained deciduous,cross bite and scissor bite were also recorded. Two interns were trained for the data collection.Data were entered to Microsoft office excel 2007 and Pearson's Chi square test was performed to justify the result using SPSS version 16 .

\section{RESULT}

A total of 239 patients were included in the study and female patients were more with $71.13 \%$ prevalence. Among them, age group of 18-30years of age was most prevalent (fig.1).The present study showed the distribution of malocclusion on the basis of Angle's classification which revealed $61.92 \%$ of Angle's class I, 33.47\% of Angle's class II and $4.60 \%$ of Angle's class III malocclusion (Table 1).Among various attributes of malocclusion, deep bite was the most common trait with $67.36 \%$ prevalence and scissor bite was least common trait with prevalence of $0.041 \%$. Increased over jet was found in $58.99 \%$ subjects and $4.6 \%$ patient had negative over jet. Under space discrepancies analysis, crowding and spacing were found in $53.13 \%$ and $35.98 \%$ cases respectively. Anterior cross bite was found in $11.71 \%$ and posterior cross bite was found in 1.2 $\%$ cases. In $1.67 \%$ cases bimax protrusion was present. Open bite was found in $4.60 \%$ of observed sample. In Angle's class I malocclusion, the most frequent trait was deep bite (66\%)whereas increased over jet(77.5\%) and crowding in (66.63\%) in Angle's class II and class III respectively. Pearson Chi square test was conducted in more frequently observed attributes to find out the relation among these attributes and sex and age which showed that none of the attributes of malocclusion were significantly related with gender and age at $\mathrm{p}<$ .05(table 2-3).

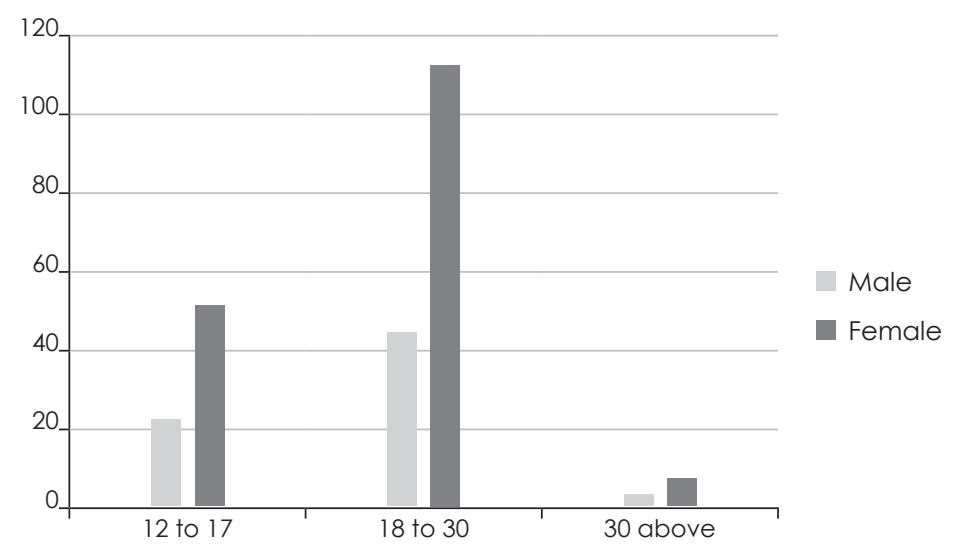

Fig.1: Distribution of sample according to Age 
Table 1: Distribution of sample according to Gender

\begin{tabular}{|l|l|c|c|c|}
\hline \multicolumn{1}{|c|}{ Gender } & Class 1 (No and percent) & Class 2 (No and percent) & Class 3 (No and percent) & Percentage \\
\hline Male & 47 & 17 & 5 & $28.87 \%$ \\
\hline Female & 101 & 63 & 6 & $71.13 \%$ \\
\hline Total & $148(61.62 \%)$ & $80(33.47 \%)$ & $11(4.6 \%)$ & $100 \%$ \\
\hline
\end{tabular}

Table 2: Distribution of different attributes of malocclusion according to gender

\begin{tabular}{|c|c|c|c|c|c|c|}
\hline Traits & Sex & Class I & Class II & Class III & Total No (\%) & Significance \\
\hline \multirow{3}{*}{$\begin{array}{l}\text { Increased } \\
\text { overjet }\end{array}$} & M & 30 & 15 & - & 45 & \multirow{3}{*}{$\begin{array}{l}x 2=3.0362 \\
p=0.168132\end{array}$} \\
\hline & $\mathrm{F}$ & 49 & 47 & - & 96 & \\
\hline & Total & 79 & 62 & - & $141(58.99)$ & \\
\hline \multirow{3}{*}{ Crowding } & M & 22 & 9 & 3 & 34 & \multirow{3}{*}{$\begin{array}{l}x 2=3.0252 \\
p=0.220336\end{array}$} \\
\hline & $\mathrm{F}$ & 50 & 39 & 4 & 93 & \\
\hline & Total & 72 & 48 & 7 & $127(53.13)$ & \\
\hline \multirow{3}{*}{ Spacing } & $M$ & 21 & 7 & 2 & 33 & \multirow{3}{*}{$\begin{array}{l}x 2=2.1557 \\
p=0.340321\end{array}$} \\
\hline & $\mathrm{F}$ & 36 & 19 & 1 & 56 & \\
\hline & Total & 58 & 25 & 3 & $86(35.98)$ & \\
\hline \multirow{3}{*}{ Deep bite } & M & 34 & 13 & 1 & 48 & \multirow{3}{*}{$\begin{array}{c}x 2=3.6122 \\
p=0.164296\end{array}$} \\
\hline & $\mathrm{F}$ & 64 & 48 & 1 & 113 & \\
\hline & Total & 98 & 61 & 2 & $161(67.36)$ & \\
\hline
\end{tabular}

Inference:The results are not statisticallysignificant at $p<.05$

Table 3: Distribution of different attributes of malocclusion according to age

\begin{tabular}{|c|c|c|c|c|c|c|}
\hline Traits & Age & Class I & Class II & Class III & Total No (\%) & Significance \\
\hline \multirow{4}{*}{$\begin{array}{l}\text { Increased } \\
\text { overjet }\end{array}$} & $a$ & 21 & 26 & - & 47 & \multirow{4}{*}{$\begin{array}{l}x 2=3.566 \\
p=0.168132\end{array}$} \\
\hline & $b$ & 53 & 34 & - & 87 & \\
\hline & C & 5 & 2 & - & 6 & \\
\hline & Total & 79 & 62 & - & 141 & \\
\hline \multirow{4}{*}{ Crowding } & $a$ & 29 & 17 & 1 & 47 & \multirow{4}{*}{$\begin{array}{l}x 2=4.4932 \\
p=0.343353\end{array}$} \\
\hline & $b$ & 41 & 30 & 5 & 76 & \\
\hline & c & 2 & 1 & 1 & 4 & \\
\hline & & 72 & 48 & 7 & 127 & \\
\hline \multirow{4}{*}{ Spacing } & $a$ & 8 & 9 & 1 & 18 & \multirow{4}{*}{$\begin{array}{l}x 2=6.0893 \\
p=0.192576\end{array}$} \\
\hline & $b$ & 44 & 15 & 2 & 61 & \\
\hline & $\mathrm{C}$ & 6 & 1 & 0 & 7 & \\
\hline & Total & 58 & 25 & 3 & 86 & \\
\hline \multirow{4}{*}{ Deep bite } & $a$ & 28 & 20 & 0 & 48 & \multirow{4}{*}{$\begin{array}{c}x 2=1.9355 \\
p=0.747615\end{array}$} \\
\hline & $\mathrm{b}$ & 65 & 40 & 2 & 105 & \\
\hline & c & 5 & 1 & 0 & 6 & \\
\hline & Total & 98 & 61 & 2 & 161 & \\
\hline
\end{tabular}

Inference: The results are not significant at $p<.05$

Note: $a=12$ to 17 yrs, $b=18-30$ yrs $c=$ more than 30 yrs)

\section{DISCUSSION}

For the management of any problem, knowledge of prevalence of the particular problems is mandatory. The prevalence of malocclusion in different parts of world is varied from $39 \%$ to $93 \% .^{4}$ Every geographical area has different prevalence of malocclusion .Study on prevalence of malocclusion in central part of Nepal had not been carried out till the date. So the study on pattern of malocclusion in OPD patient of orthodontic departments of two medical colleges in Chitwan had been done. Prevalent age groups of orthodontic patients weremostly 18-30 years which were usual finding as in other studies.

The result of the present study showed that females were more interested toward orthodontic treatment with the frequency of $71.3 \%$ in the central part of Nepal as in western and eastern part of Nepal where the frequency of interested female to male ratio was 2:1.5,6 Similar study done in Bangladesh found that females between the age of 15 to 20 were most prevalent 
seeking orthodontic treatment,almost twice than the males in the same group. It was suggested the causes could vary from self-consciousness to social and matrimonial reasons.?

The most frequent malocclusion was Angle's class I malocclusion (61.62\%) followed by Angle's class II andAngle's class III malocclusion which were in consensus with the reports of other studies. ${ }^{5,6,8,9}$ Whereas according to a hospital based study done in Pakistan, Angle'sclass II malocclusion was the most frequent among all patients (70.5\%) and Angle's class I and III were $18.6 \%$ and $10.9 \%$ respectively. The most frequently encountered attributewas increased overjet. ${ }^{10}$

Most frequently observed occlusal attributes in all type of malocclusion was deep bite (67.36\%) followed by increased over jet, crowding, spacing,anterior cross bite, open bite, posterior cross bite and scissor bite in decreasing order. In contrast, crowding (52.9\%) was the most prevalent and deep bite (40\%) was third most frequently seen attributes of malocclusion in eastern part of Nepalandover jet (43.8\%) was most common and deep bite (8.2\%) was very less frequent in the study conducted in Kantipur dental college, Kathmandu., ${ }^{9,11}$

In the present study, none of the attributes of malocclusion are dependent on gender and age of patient statistically.Similarly, Gul-e-Erum also reported no statistically significant differences in malocclusion distribution between males and females where as in the study conducted by Birgit Thilander, overjet, spacing and tooth size were more frequent in boys and crowding was more frequent in girls. ${ }^{4,10}$ Maryam Akbari et al also reported the higher prevalence of malocclusion in girls in their systematic review and meta-analysis on prevalence of malocclusion among Iranian children. ${ }^{12}$ The study conducted in western part of Nepal showed the relation between distribution of malocclusion and age was statistically significant but the association of distribution of malocclusion with gender was not statistically significant. ${ }^{5}$

\section{CONCLUSION}

Angles Class I malocclusion was most prevalent with least common class III malocclusion .Deep bite was most common attributes with least prevalent scissor bite. No statistically significant relationship was found between different attributes of malocclusion and gender and age of patients.

\section{REFERENCES}

1. Hassan R, Rahimah AK. Occlusion, malocclusion and method of measurements-an overview. Archives of Orofacial science.2007; $2: 3-9$.

2. Basha S, Mohamed RN, Swamy HS, Parameshwarappa P, Untreated. Gross Dental Malocclusion in Adolescents: Psychological Impact and Effect on Academic Performance in School Oral health \& preventive dentistry. 2016, Vol-14, Issue 1: P. 63

3. Kitafusa Y. Occlusal pattern in orthodontic patients: using the occlusal force measuring system. In: Nanda R, Kapila S, Current therapy in orthodontics. Missoury: Mosby, Inc.; 2010. P. 27-35

4. Thilander B, Pena L, Infante C, Parada SS, de Mayorga C. Prevalence of malocclusion and orthodontic treatment need in children and adolescent in Bogota, Colombia. An epidemiological study related to different stages of dental development. Euro J Orthod. 2001 ; 23:153-167.

5. Halwai HK, Gautam V. Distribution of Malocclusion Traits among Orthodontic Patients in a Tertiary Care Center of Western Nepal. Orthodontic Journal of Nepal. 2017; 7 (1):11-13.

6. Sharma JN. Epidemiology of malocclusions and assessment of orthodontic treatment need for the population of eastern Nepal.World J Orthod. 2009 winter; 10(4):311-6

7. Rahman MM, Jahan H, Hossain MZ. Pattern of malocclusion in patients seeking orthodontic treatment at Dhaka Dental College and Hospital. Ban J Orthod and DentofacOrthop,2013Apr:Vol-3N0.2: P. 9-11

8. Mohanty P, Dany SS, Acharya SS, Shaoo N, Das SK, and Chatarjee S, et al. Pattern of malocclusion in orthodontic patients: A multi Centre study. J Int Oral Health 2016; 8(12): P. 1105-1109.

9. Sharma J. Pattern of distribution of malocclusion in patients seeking orthodontic treatment at BPKISH from Sunsari district of Nepal. Health Renaissance.2010 may-Aug 21; 8(2):93-6.

10. Gul-e-Erum, Fida, M. Pattern of malocclusion in orthodontic patients: a hospital based study. J of Ayub Medical College 2008; 20(1): P.43-7.

11. Shrestha S, Shrestha RM. An analysis of malocclusion and occlusal characteristics in Nepalese orthodontic patients. Orthodontic Journal of Nepal. 2013 June; vol.3, .1.

12. Akbari M. , Lankarani KB ,Honarvar B, Tabrizi R, Mirhadi H, Moosazadeh M. Prevalence of malocclusion among Iranian children: A systematic review and meta-Analysis.Dental research journal. 2016 September 13 (5):387-395. 